\title{
COVID-19: minimising risk to healthcare workers during aerosol-producing respiratory therapy using an innovative constant flow canopy
}

To the Editor:

Noninvasive ventilation (NIV), continuous positive airway pressure (CPAP) and high-flow nasal cannula (HFNC) can be used as the first line of treatment in coronavirus disease 2019 (COVID-19) patients with respiratory failure, postponing and maybe even avoiding the need for intubation and mechanical ventilation [1]. Recent systematic review and meta-analysis demonstrated that HFNC reduces the need for intubation compared with conventional oxygen, with no change in the death risk or length of stay in the intensive care unit [2,3]. No direct evidence supports the use of NIV, due to a high failure rate [4]. However, when resources become limited, with no option of invasive ventilation, the use of NIV may be justified. The major caveat of using noninvasive respiratory support in the face of the COVID-19 pandemic is the generation of aerosols, composed of small virus-containing particles, which may remain suspended in the air, with increased risk for healthcare workers [5, 6]. The risk of aerosolisation depends on many variables, including duration of use, flow velocity, mask leakage and patient coughing and cooperation.

In the current crisis, with a limited number of ventilators and of negative pressure facilities, we developed a novel way to reduce, and even eliminate, this exposure to potentially dangerous aerosols by using a constant flow canopy over the upper part of the patient bed, thus creating a confined area surrounding the patient in which noninvasive respiratory support can be safely used (figure 1).

The system is composed of the following three parts. 1) A flexible plastic canopy that covers the upper part of the patient body. 2) A fan filtering unit composed of a pre-filler in the air inlet, an electrical fan, and a high-efficiency particulate air (HEPA) filter in the air outlet (identical to those installed in biological cabinets). The filtering system is manufactured by ULPA Cleanrooms \& Laboratories Ltd, Haifa, Israel. 3) An exhaust system (electrical fan) creating negative pressure and transferring the filtered air out to the open atmosphere. Each filtering unit can support up to four patients in parallel.

The polyethylene canopy serves as physical barrier between the healthcare worker and the patient. The canopy should ensure maximum enclosure of the patient's upper body; however, a gap of 5-7 cm between the patient's body and the canopy is designed to enable safe treatment. The system enables rapid access in case of an emergency, from either the direction of the chest or head, enabling rapid intubation or cardiopulmonary resuscitation.

The unit was evaluated by two techniques. 1) Face velocity and smoke direction: speed $\left(\mathrm{m} \cdot \mathrm{s}^{-1}\right)$ of air flowing perpendicular to the hood's opening inside the enclosure, and smoke flow in the direction of the enclosure back part (according to US ASE/ASHRAE Standard 110). 2) Integrity test of the HEPA filtering unit, using photometry, to measure leakage of particles $(0.3-0.5 \mathrm{um}$ in size) through the filters (according to EN 12469 European Standard for Microbiological Safety Cabinets).

The results of our evaluation demonstrated that the average air flow velocity was $4.4 \mathrm{~m} \cdot \mathrm{s}^{-1}$ and the smoke clearly flows very fast into the back side of the canopy. The integrity results measured $0.0006 \%$ particles (maximum standard requirement $0.01 \%$ ).

@ERSpublications

An innovative constant flow canopy enables noninvasive respiratory support with minimal risk of healthcare worker infection https://bit.ly/3eqgoVZ

Cite this article as: Adir Y, Segol O, Kompaniets D, et al. COVID-19: minimising risk to healthcare workers during aerosol-producing respiratory therapy using an innovative constant flow canopy. Eur Respir J 2020; 55: 2001017 [https://doi.org/10.1183/13993003.01017-2020]. 


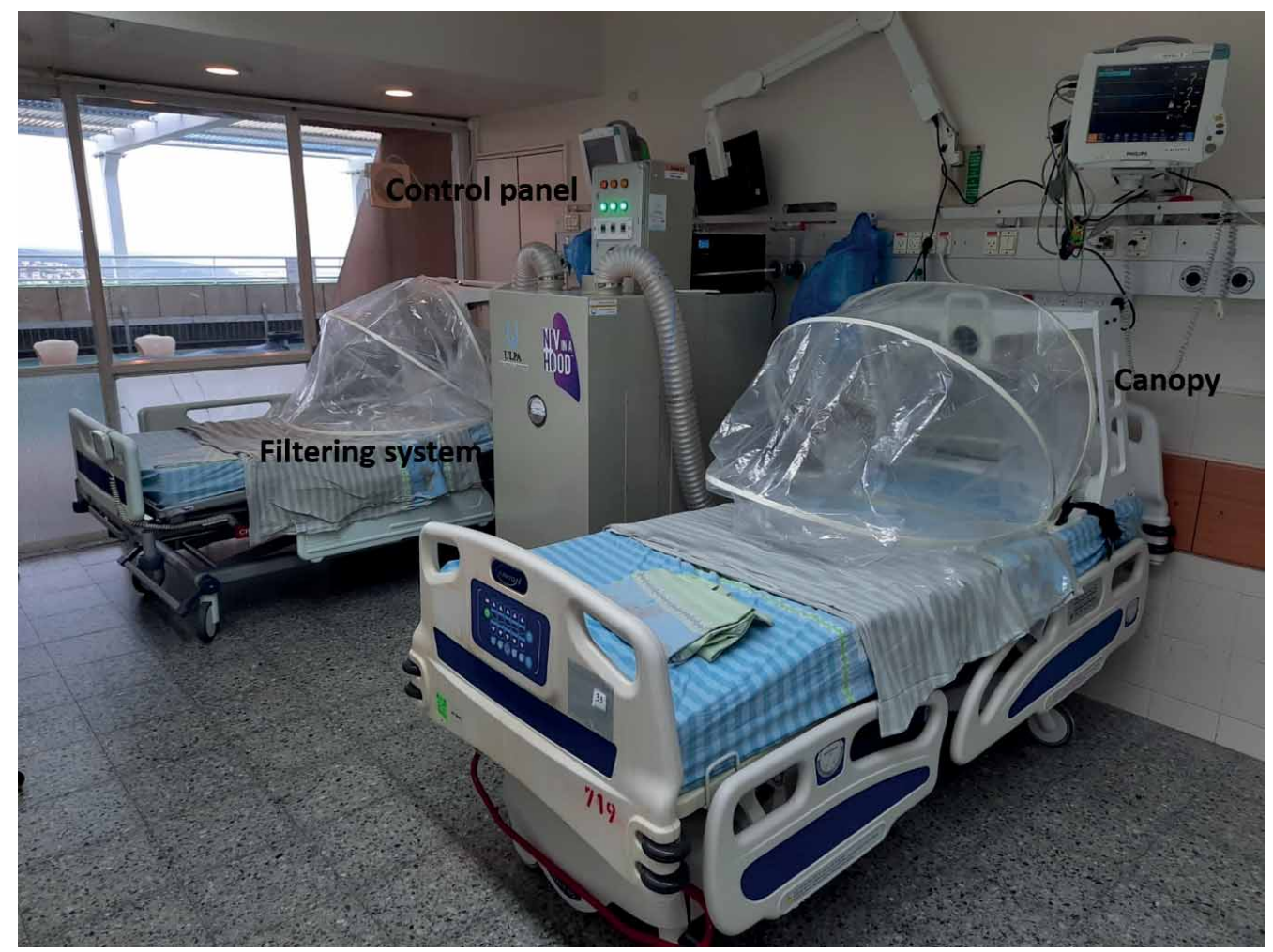

FIGURE 1 The constant flow canopy system.

In order to assess the satisfaction of the medical staff in the coronavirus unit with the system, we asked nine physicians and nurses to fill a short six-question questionnaire. The overall impression score of the system was 9.1 (out of 10).

In summary, this innovative negative pressure canopy allows us to administer NIV, CPAP or HFNC to patients with moderate to severe lung injury due to severe acute respiratory syndrome coronavirus 2 (SARS-CoV-2) infection, with minimal risk to healthcare workers. The system has been installed in the coronavirus unit of the Lady Davis Carmel Medical Center, Haifa, Israel.

Yochai Adir $^{1,2}$, Ori Segol ${ }^{1,2}$, Dmitry Kompaniets ${ }^{1,2}$, Hadas Ziso ${ }^{3}$, Yechiam Yaffe ${ }^{4}$, Irina Bergman ${ }^{1,2}$, Erez Hassidov ${ }^{3}$ and Arieh Eden ${ }^{1,2}$

${ }^{1}$ Lady Davis Carmel Medical Center, Pulmonary Division, Haifa, Israel. ${ }^{2}$ The Faculty of Medicine, Technion Institute of Technology, Haifa, Israel. ${ }^{3}$ Tamar Robotic LTD, Yagur, Israel. ${ }^{4}$ Yafit Safety \& Environment, Mevasseret Zion, Israel.

Correspondence: Yochai Adir, Lady Davis Carmel Medical Center, Pulmonary Division, 7 Micahl St, Haifa, 3436212, Israel. E-mail: adir-sh@zahav.net.il

Received: 4 April 2020 | Accepted after revision: 9 April 2020

Conflict of interest: Y. Adir received personal fees for lecturing and/or consulting from Actelion, Boehringer Ingelheim, Teva, Bayer, GSK, Roche, Novartis, AstraZeneca, Kamada and UT Pharmaceuticals, and research grants from Actelion, Bayer, Boehringer Ingelheim and GSK. O. Segol has nothing to disclose. D. Kompaniets has nothing to disclose. H. Ziso reports that the Israeli innovation authority have granted funds to Tamar Robotics Ltd, such funds along with the funds allocated by our investors were used to develop the system presented in this paper; H. Ziso has a US Provisional Patent Application number 63/001,562, Israel Patent Application number 273616, entitled: "Portable Patient Hood System For Protection Of Medical Staff And Others From Infectious Disease Transmission" pending, and a US Provisional Patent Application number 62/994,614 entitled: "Portable Patient Hood System For Protection Of Medical Staff And Others From Infectious Disease Transmission" pending; and would like to state that: 1) the author is an employee of Tamar Robotics Ltd, that developed the system presented in the paper as a VP of R\&D; 2) the author is co-founder of Tamar Robotics Ltd and has holdings in the company (less than 6\%); 3) Tamar Niv Breathing Solutions Ltd may sell this product in the future and the author will be receiving dividend or royalties if such sales are made in the future. Y. Yaffe has nothing to disclose. I. Bergman has nothing to disclose. E. Hassidov reports that the Israeli innovation authority have granted funds to Tamar Robotics Ltd, such funds along with funds allocated by our investors were used to develop the system presented in this paper; E. Hassidov has a US Provisional Patent Application number 63/001,562, Israel Patent Application number 273616, entitled: "Portable Patient Hood System For Protection Of Medical Staff And Others From Infectious Disease Transmission" pending, and a US Provisional Patent Application number 62/994,614 
entitled: "Portable Patient Hood System For Protection Of Medical Staff And Others From Infectious Disease Transmission" pending; and would like to state that: 1) the author is a part-time employee of Tamar Robotics Ltd that developed the system presented in the paper; 2) the author's brother is Noam Hassidov, CEO of Tamar Robotics Ltd; 3) the author is a fifth year student in the Bar Illan medical school in Israel; 4) the author works once a week in the ER of Carmel Medical Center as an assistant physician; 5) the author has no holdings in Tamar Robotics or any other companies related to the system presented in this paper; 6) Tamar Niv Breathing Solutions Ltd may sell this product in the future. A. Eden has nothing to disclose.

\section{References}

1 Critical care committee of Chinese Association of Chest Physician; Respiratory and critical care group of Chinese Thoracic Society; Respiratory care group of Chinese Thoracic Society. [Conventional respiratory support therapy for severe acute respiratory infections (SARI): clinical indications and nosocomial infection prevention and control]. Zhonghua Jie He He Hu Xi Za Zhi 2020; 43: 189-194.

$2 \mathrm{Ni}$ YN, Luo J, Yu H, et al. The effect of high-flow nasal cannula in reducing the mortality and the rate of endotracheal intubation when used before mechanical ventilation compared with conventional oxygen therapy and noninvasive positive pressure ventilation. A systematic review and meta-analysis. Am J Emerg Med 2018; 36: 226-233.

3 Rochwerg B, Granton D, Wang DX, et al. High flow nasal cannula compared with conventional oxygen therapy for acute hypoxemic respiratory failure: a systematic review and meta-analysis. Intensive Care Med 2019; 45: 563-572.

4 Esquinas AM, Egbert Pravinkumar S, Scala R, et al. Noninvasive mechanical ventilation in high-risk pulmonary infections: a clinical review. Eur Respir Rev 2014; 23: 427-438.

5 Wax RS, Christian MD. Practical recommendations for critical care and anesthesiology teams caring for novel coronavirus (2019-nCoV) patients. Can J Anaesth 2020; 67: 568-576.

6 Guan L, Zhou L, Zhang J, et al. More awareness is needed for severe acute respiratory syndrome coronavirus 2019 transmission through exhaled air during non-invasive respiratory support: experience from China. Eur Respir J 2020; 55: 2000352. 